\title{
Feasibility of Power Control for Multi-Channel User in Inter- Femtocell Network
}

\author{
Anggun Fitrian Isnawati ${ }^{1,2}$, Risanuri Hidayat ${ }^{1}$, Selo Sulistyo ${ }^{1}$, I Wayan Mustika ${ }^{1}$ \\ ${ }^{1}$ Departement of Electrical and Information Technology, Gadjah Mada University (UGM), Yogyakarta, Indonesia \\ ${ }^{2}$ Telkom School of Telematics (ST3 Telkom), Purwokerto, Indonesia
}

\begin{tabular}{|c|c|}
\hline Article Info & ABSTRACT \\
\hline Article history: & \multirow{10}{*}{$\begin{array}{l}\text { The importance of power control feasibility is closely related to the direct } \\
\text { implementation of femtocell technology, which is related to interference } \\
\text { between users and to the optimal power usage to transmit which at the end it } \\
\text { can save power and introduce a long-lasting battery. The power control } \\
\text { feasibility study done in this paper is focused on a centralized femtocell } \\
\text { network with a multi-channel user. The research method is based on the use } \\
\text { of feasible solution algorithms by observing the output of power vector that } \\
\text { should be a non-negative number. A non negative number indicates that } \\
\text { power can be implemented. The result of this study indicates that all users } \\
\text { can reach the specified SINR targets. SINR users will increase when there } \\
\text { are additional channels for user groups. Moreover, the average power will } \\
\text { also decrease while increasing the amount of provided channels. The greater } \\
\text { number of users in a user group, the less SINR can be obtained. } \\
\text { Copyright } @ 2016 \text { Institute of Advanced Engineering and Science. } \\
\text { All rights reserved. }\end{array}$} \\
\hline Received Feb 17, 2016 & \\
\hline Revised Mar 27, 2016 & \\
\hline Accepted Apr 14, 2016 & \\
\hline \multirow{6}{*}{$\begin{array}{l}\text { Keyword: } \\
\text { Feasibility } \\
\text { Femtocell } \\
\text { Multi-channel } \\
\text { Power control } \\
\text { SINR }\end{array}$} & \\
\hline & \\
\hline & \\
\hline & \\
\hline & \\
\hline & \\
\hline \multicolumn{2}{|l|}{ Corresponding Author: } \\
\hline \multicolumn{2}{|c|}{$\begin{array}{l}\text { Anggun Fitrian Isnawati, } \\
\text { Departement of Electrical and Information Technology, } \\
\text { Gadjah Mada University (UGM), } \\
\text { Yogyakarta, Indonesia. } \\
\text { Email: anggun.s3te13@mail.ugm.ac.id }\end{array}$} \\
\hline
\end{tabular}

\section{INTRODUCTION}

Femtocell technology has an increasingly important role today and reseach in this field is a big challenge. It has several advantages in terms of it can be installed not only in the server side but also in the subscriber side, so it can be used to improve network performances concerning indoor coverage. The femtocell network can also be connected to broadband network service providers such as digital subscriber line (DSL), cable modem or radio frequency (RF). Femtocell technology has also benefits in terms of overcoming the scarcity of spectrum frequencies. It can share spectrum with macrocell network, but still can avoid interference among femtocell users or between femtocell users and macrocell users [1].

One thing that stands out to study on femtocell technology is on its power control scheme. Power control shows its role in the development of femtocell networks, especially in ad hoc nature and quality of service [2]. The communication networks, either centralized or decentralized want to transmit and receive data in the best level of QoS (quality of service) even in the minimum power signals. Some references mention that centralized power control in mobile communication is limited in the practice implementation [3]. However, the comparison with distributed power control scheme can be done [4]. The influence of nearfar effect using frequency reuse is also related to the feasibility of signal to interference plus noise ratio (SINR) in a femtocell network [5].

A feasibility test of power control scheme is done to ensure that all users can achieve SINR targets in a femtocell network. The test is not only performed using one channel in a group, but also using multiple channels, and can be done either on a centralized or a distributed network. If the calculated power transmit does not meet the feasibility results (non-negative power vector) that still in negative value, then have to re- 
adjust the parameters [4]. Research on centralized and distributed power control has been carried out by several studies [3],[6],[7].

In the previous study [8], there was a power control scheme that uses a feasible solution algorithm on one channel only. Fundamentally, the feasibility test should not only be done on one group of users with a single channel but also can be done on the users by using multi-channels that will be divided into several groups of users. In this paper, the centralized power control scheme for multi-channel users in femtocell network is studied. The feasibility test of multi-channel user is to be important to be done because it is associated with femtocell network topology and also associated with characteristics of femtocell users who use the division of RBs as the transmission channel. Feasibility test is intended for each femtocell user to be able to achieve the target SINR.

Organization of this paper is structured as follows. The system model of this study is described in Section 2, and Section 3 explains the feasibility of power control for the multi-channel user in inter-femtocell network. Section 4 shows the simulation results, and the conclusion is presented in section 5 .

\section{SYSTEM MODEL}

The studied femtocell network in this paper consists of several FAPs as a receiver and several FUEs as a transmitter. Due to the use of the channels that should not be the same in a femtocell, then use the same channel can only be done by the user in the different femtocell. In the femtocell network, every user is only affected by interference from another femtocell user, as illustrated in Figure 1.

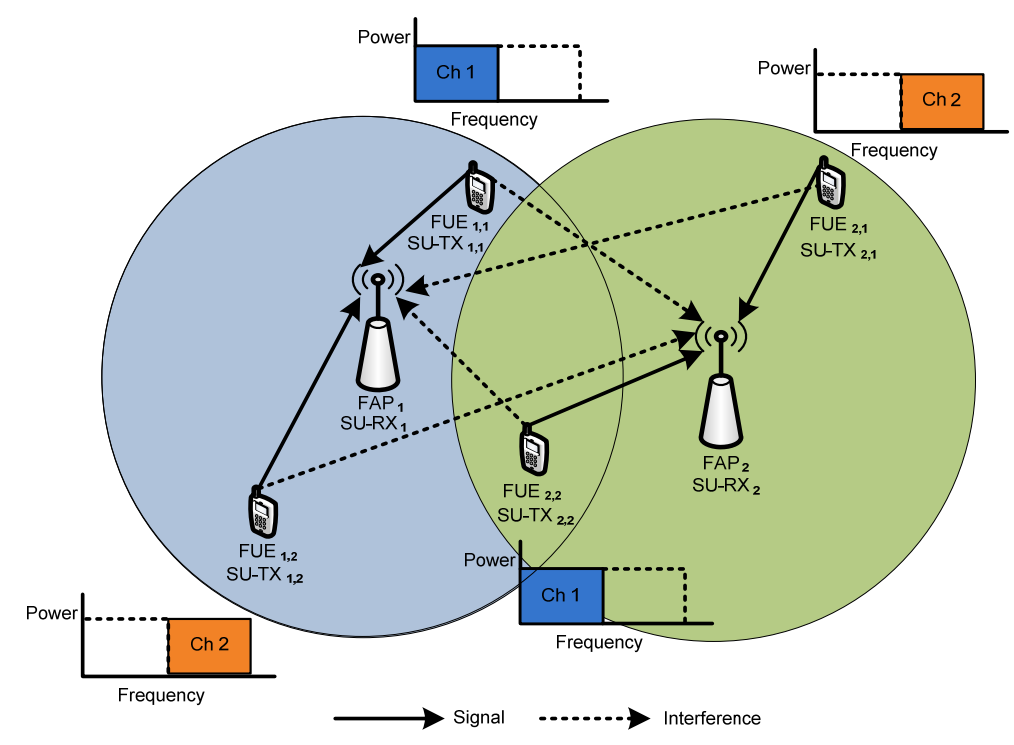

Figure 1. System model of multi channel user in inter-femtocell network

We focus on the femtocell users (femto users) or secondary users (SU) in cognitive radio technology. They are referred to as the secondary user (SU) because the users are using a channel that is not being utilized by the primary user (PU), which in this case, is the macrocell user (macro user). Based on Figure 1, it can be explained that for channel $1\left(\mathrm{Ch}_{1}\right)$, when the transmitter $\mathrm{FUE}_{1,1}$ (SU Transmitter, $\left.\mathrm{SUTX}_{1,1}\right)$ sends a signal to the receiver $\mathrm{FAP}_{1}\left(\mathrm{SU}\right.$ Receiver, $\left.\mathrm{SURX} \mathrm{X}_{1}\right)$, the interference occurs on the receiver $\mathrm{FAP}_{2}$ $\left(\mathrm{SURX}_{2}\right)$. Due to this interference, transmitter $\mathrm{FUE}_{2,2}\left(\mathrm{SUTX}_{2,2}\right)$ has to raise the transmit power so it can achieve target SINR. This condition also applies to channel $2\left(\mathrm{Ch}_{2}\right)$ and will be sustained, so that it requires for power control.

In the case of inter-femtocell network, each femtocell user would be affected by interference from neighboring femtocell users, which is caused by the use of the same channel. As seen in Figure 1, the user $\mathrm{FUE}_{1,1}$ and $\mathrm{FUE}_{2,2}$ using the same channel, $\mathrm{Ch}_{1}$, thus interfere with each other. Similarly, user FUE $\mathrm{F}_{2,1}$ who will be affected by interference from user $\mathrm{FUE}_{1,2}$ because both use the same channel, $\mathrm{Ch}_{2}$. 
In this paper, five pairs of users were spread randomly by the user distance set by femtocell network configurations within the macrocell coverage, as shown in Figure 2. From the system model, there are some pairs of user transmitter and receiver. The solid lines represent the communication path, while the dashed lines indicate the interference path, as shown in Figure 1. Link gain between the FUE $\mathrm{i}$ and the FAP $\mathrm{i}$ is represented by $\mathrm{g}_{\mathrm{ii}}$. The gain of the link between the FUE $\mathrm{j}$ and the FAP $\mathrm{i}$ is represented by $\mathrm{g}_{\mathrm{ij}}$. For a simple notation, it is assumed that the interference and noise are combined and declared as $\sigma_{0}$. Let $p_{j}$ is the transmission power of FUE $i$ and $\mathbf{p}_{i}$ is the power of other FUEs. Therefore, the expected SINR of user $i \gamma_{i}$ can be defined as [9]:

$$
\gamma_{i}=\frac{f_{i} g_{i}}{\sum_{i=1, i=j}^{N} j g_{i j}+\sigma_{0}}
$$

where $\Phi_{0}$ is average of noise level and is the same for all receivers.

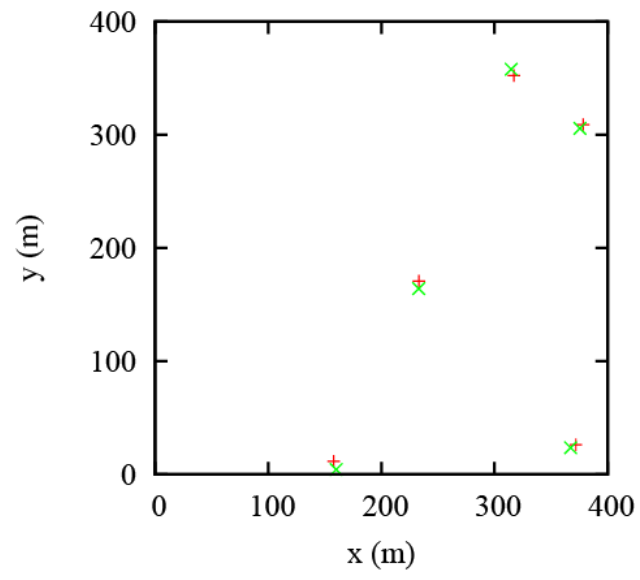

Figure 2. Femtocell user topology

\section{FEASIBILITY OF POWER CONTROL FOR MULTI-CHANNEL USER}

Interference management scheme in femtocell network is divided into co-tier and cross-tier interference. From the distribution of such schemes, the inter-femtocell network includes the co-tier scheme of uplink interference so as to be able to use both Code Division Multiple Access (CDMA) and Orthogonal Frequency Division Multiple Access (OFDMA).

In the OFDMA femtocell network, the study of power control is also distinguished by the channel usages, which is a single-channel or a multiple-channel, where each user can allocate transmit power through multiple frequency bands [10]. In the matter of OFDMA femtocell, it depends on the subchannels allocation. In LTE femtocell, sub-channels known as Resource Blocks (RBs). If the resource blocks (RBs) were exhausted in femtocells, femtocells would use other sub-channels [11] and if among user uses the different sub-channels, the interference would be avoided [12]. Subchannels allocation can be implemented by subchannel selection algorithm such as Experience-Weighted Attraction (EWA) algorithm [13] and game theory method [14],[15].

Besides considering the interference factors, the complexity in the implementation also affects the decision of its application. In practice, the centralized network requires a central station and global information of all user channels. Similarly, the centralized power control will need comprehensive control signals in the network, so it is hard to be carried out, particularly for the ad-hoc wireless network. The complexity of the centralized networks occurr because the process of computing at the base station is too much, which is related to the processing of all information from the environment and the users [16]. Therefore, the implementation of distributed systems that use only local information would be more realistic to be applied [17]. However, these two different schemes require feasibility test at the time before it will be implemented, as seen in Figure 3. 


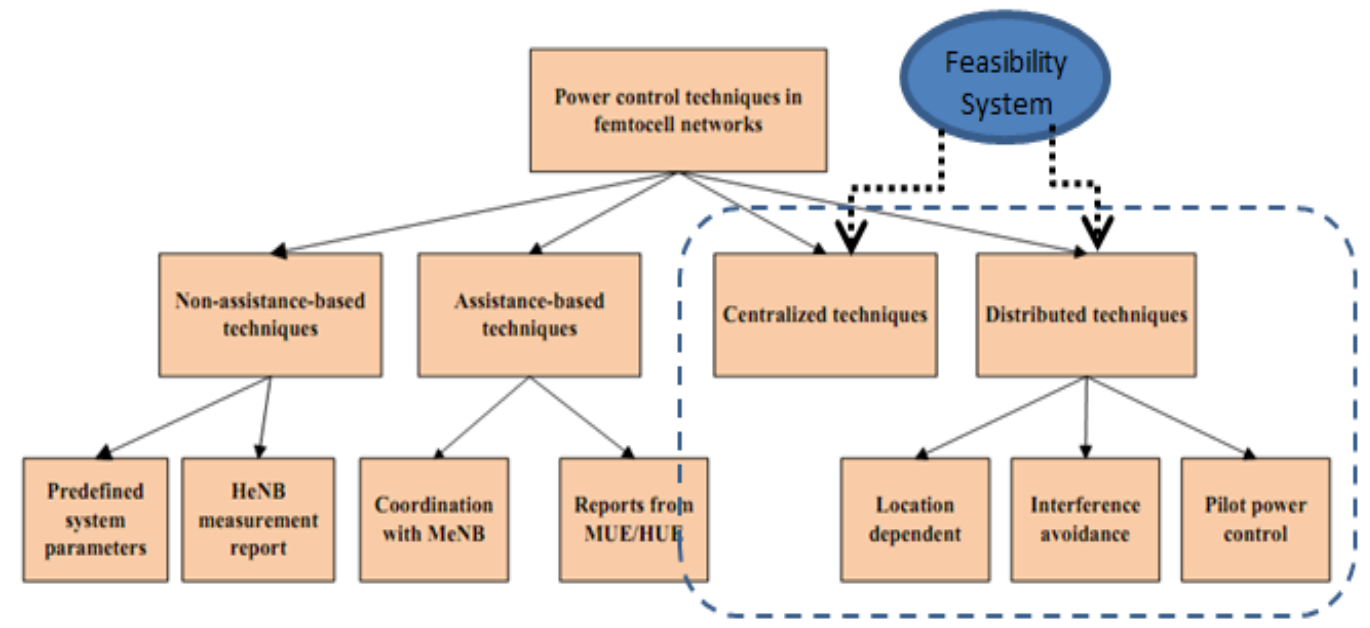

Figure 3. Feasibility test for centralized and distributed scheme [16]

\subsection{Feasibility in Centralized Power Control}

If there is transmission channel with a frequency $\mathrm{K}, \mathrm{K}<\mathrm{N}$, so that expected SINR of the user i from the equation (1) can be redefined as [8],[9]:

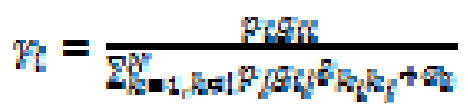

where $\rho_{0}$ is average of noise level and same for all receivers. $\delta_{\mathrm{kgkj}}$ is the interference function that shows the interference that occurs between the user $i$ and $j$, and is defined as:

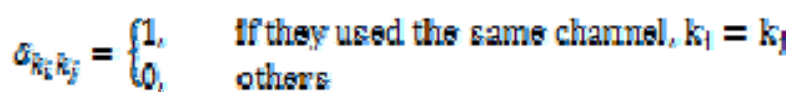

On the physical layer, power control can minimize the interference and for a feasible system, the results of all users must meet the determined SIR. Users can adjust their transmit power level to the distributed power control to make sure that all users who share the same channel meet the requirements of the target SIR $\left(\gamma \mathrm{fr}_{\mathrm{i}}\right.$ to the expected receiver.

To fulfill the requirements of QoS for the specified communications in femtocell network, we must be considered making sure that the SINR of each user $\gamma_{i}$ always be greater than the threshold SINR:

$$
F^{2} \geq F^{r r} \quad \forall i \in N
$$

For users who share the same frequency channel, transmission power will affect the quality of the link and the temperature noise in a particular channel. Therefore, the purpose of power control is to set the transmit power of all users in improving the quality of link that allows user groups to transmit data through the same channel to reach the bit error rate (BER) target.

Feasibility of power control is based upon the following equation [9]:

$$
F^{*}=(t-H)^{-1} \eta
$$

If given the target SIR $\gamma^{*}$, for achieving the feasible condition, it is necessary to meet the requirements of non-negative power vector $\mathrm{P}^{*}$, with $\boldsymbol{H}=\left(\mathrm{h}_{11}\right)$ is normalized link gain matrix and satisfied the equation below:

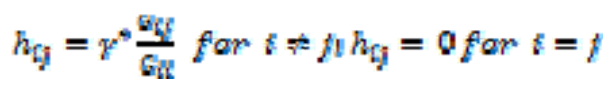

and $\eta=\left(\eta_{1}\right)$ is normalized noise vector that fulfilled this equation: 


$$
\eta_{t}=\gamma^{s} \frac{g}{\sigma_{n}}
$$

For users who share the same frequency channel, the transmission power will affect the quality of the link and the temperature disturbance in a certain channel. The purpose of the power control is adjusting the transmit power in all users for improving the quality of relationships that allow the users group to transmit through the same channels so it can meet the specified BER.

Based on equation (4) about a feasible solution in single-channel user group, then the equation can be developed into a feasible solution to the multi-channel user as follows:

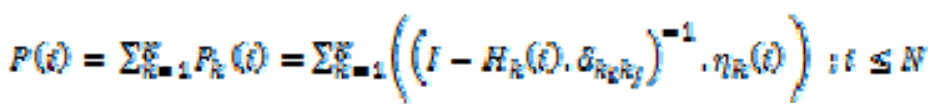

where $\mathrm{K}$ is total number of channel, $\mathrm{k}$ is channel number, and $\mathrm{s}_{\mathrm{k}_{\mathrm{l}} \mathrm{k}}$ is function of user interference.

\subsection{Feasibility in Distributed Power Control}

Feasibility test for the distributed power control (DPC) is shown by testing the convergence of an iterative algorithm. The equation used to verify the convergence introduced by Yates [6]. Power control in distributed scheme refers to the study of Yates [6], which proves the convergence of the DPC algorithm based on standard interference function:

$$
P^{[m+1]}=\left(\left[P^{[n]}\right)\right.
$$

where I is the interference function that defines power vector in the next iteration. Interference function is named standard if it meets all of a non-negative power vector:
1) Positivity
$I\left(P^{2}\right)>0$
2) Monotonicity
$\mathrm{P}^{\mathrm{x}} \geq \mathrm{P}^{\mathrm{r}}-\mathrm{I}(\mathrm{P}) \geq \mathrm{I}\left(\mathrm{P}^{\mathrm{r}}\right)$
3) Scalability
$\forall \alpha>1 \rightarrow \alpha \cdot I(P)>I(\alpha P)$

If the system is feasible, then the power vector of standard interference function would converge to minimum solution power vector $\mathrm{P}^{*}$, which is indicated by a non-negative power vector and geometric convergence speed.

Based on the algorithm Foschini-Miljanic [18] can be concluded that as long as there is a feasible vector P* then the DPC iteration algorithm of the link in the network will always result in rapid convergence towards $\mathrm{P}^{*}$. The algorithm can be written as follows:

$$
P_{l}(k+1)=\frac{\psi_{k}}{R_{l}} R_{l}(k)
$$

where $\mathrm{k}$ is a discrete time index, $\mathrm{\gamma} i$ is minimum SINR threshold for link $i$ and $\boldsymbol{R}_{i}$ is SINR user $i$. If the vector

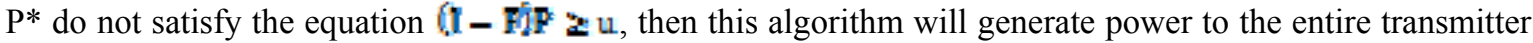
becomes infinite (infeasible).

Foschini-Miljanic (FM) algorithm showed that the scheme of DPC will be convergence towards a feasible condition when feasible solution exists [19]. Iteration scheme proposed by FM:

$$
p(n+1)=p(n)-\beta\left(l-\psi F^{2}\right) p(n)+\beta w m_{0}
$$

where $\beta$ is a parameter that is chosen to achieve convergence.

Because the Jacobian iteration produces slow convergence so as to get better faster convergence using iterative algorithms Foschini Miljanic [20] and also show an alternative to prove the convergence besides Yates [6].

Furthermore, DPC can be done by using the game theory method and get the convergence condition can be done based on an iterative algorithm of power control derived from utility function, which is the differential value of the utility function toward the power transmit function [21]-[23]. 


\section{RESULTS AND ANALYSIS}

Based on the femtocell user topology in Figure 2, the performance of the proposed power control scheme is checked. Assumed that group of five transmitter-receiver pairs of secondary users is communicating with each other in a 400 square meters area.

This part will show some of the results of the feasibility test of femtocell networks that associated to power control based on the network topology in Figure 2. Feasibility test of the system is done to ensure that the system is feasible with the power vector is non-negative, which means in practice, the system can meet the requirements of SINR.

This paper is a continuation from previous paper [24] that focused on the scheme of power vector in a user group, where there are two schemes for the single channel usage with a multi-user, namely the small user group (with 5 users per channel) and the big user group (with 15 users per channel). The prevoius paper has emphasized on achieving the different SINR target according to the size of user group. When the user group size is big (a lot of users who use the same channel), the SINR targets that can be achieved user is getting smaller, and vice versa when the user group size is small (little user who use the same channel) then the user is able to achieve greater SINR target.

Unlike previous studies that focus on one channel, this study focused on the scheme of multichannel usage. Channel usage scheme in this study are divided into three types, namely: 1) scheme of singlechannel multi-user where one channel is used simultaneously by multiple users; 2) scheme of multi-channel multi-user wherein each user group only uses the same channel, and 3) scheme of multi-channel single-user where each user can use more than one channel.

Figure 4 is representation of scheme 1. It shows the usage impact of power control feasibility method to the achievement of the target SINR, if it compared between before and after using this method. Figure 4 explains that when the condition feasible then the entire user can get the SINR target, which is equal to $22.2 \mathrm{~dB}$ while in the initial condition there are users who do not meet the target SINR, as shown by user 1 . Besides, the result also shows that the initial power has an uneven distribution of power output compared to feasible solution power control.

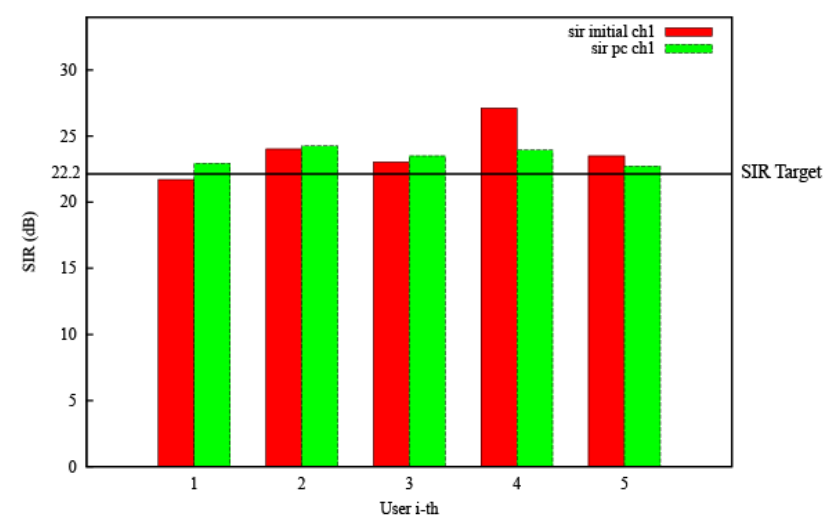

Figure 4. Achievement of target SIR between after and before using feasible solution scheme

Figure 5 is the representation of scheme 2. It shows the effect of channel addition to the user group will tend to increase the SINR of each user. From that figure, we can compare the SINR achieved by five users when using one channel (red bars), two channels (green bars) and three channels (blue bars). When we use three channels for 5 users, then channel 1 for user 1 and 2, channel 2 for user 3 and 4, and channel 3 only for user 5 . It can be seen that at the time one channel only used by one user (single-channel single-user) will obtain the maximum SINR, as shown in the user 5. It shows the SINR that greater than $80 \mathrm{~dB}$, so it can be used for video communications.

Figure 6 is the representation of scheme 3. It shows the usage of multi channels in each user. From Figure 6 it can be seen the value of SINR in users 3 and 4, that when users use a multi-channel (two channels) then it will have a higher total SINR than single channel SINR. It because of each channel has SINR that can be accumulated as a total SINR in each user. As a whole of schemes, this scheme is the best scheme that will be able to increase the total SINR per user if it compared to the SIR of each user in others scheme. 


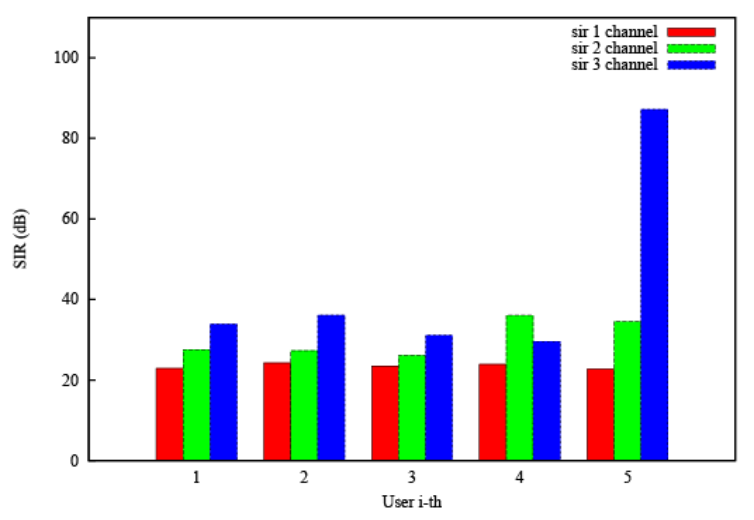

Figure 5. SIR of multi-channel multi-user

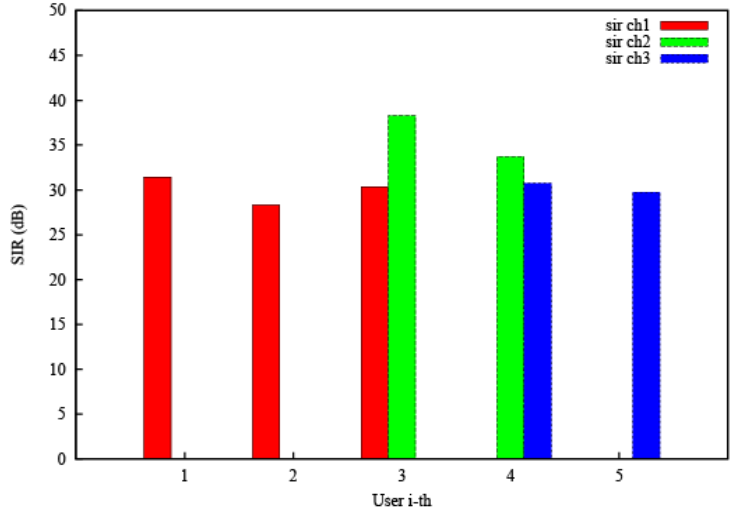

Figure 6. Multi-channel usage of users

The average power of user will decrease while increasing the number of provided channels, as shown in Figure 7. This is due to the increasing channel makes the user attempted to get the channel is not as hard as the user when compete with a lot of user in single channel. There are times when the additional channels do not affect to the power reductions of users. This is due to the user needs only a fulfillment of SINR targets, so if the target SINR has been reached then additional channel does not have significant influence. By contrast, when the target SIR of the user is raised, the user power will also increase as shown in Figure 8. This is because the user will try even harder to get enough power transmits condition so as to achieve a higher target SIR and quality service better.

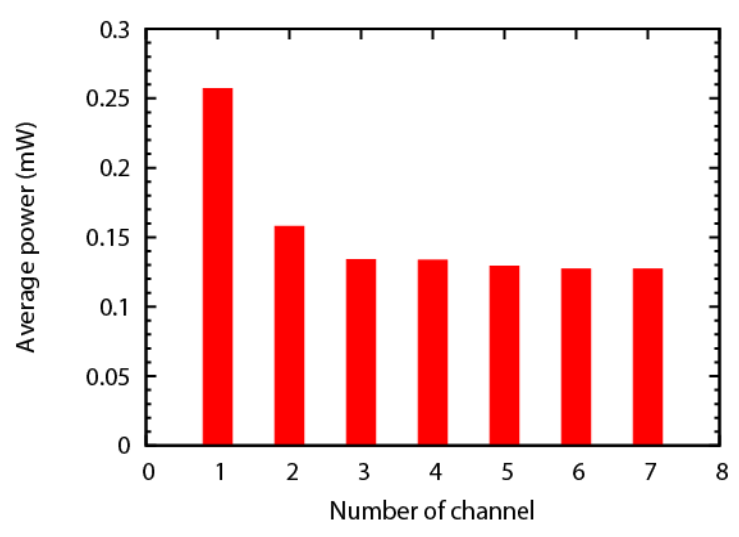

Figure 7. Average power when the number of channel is changed

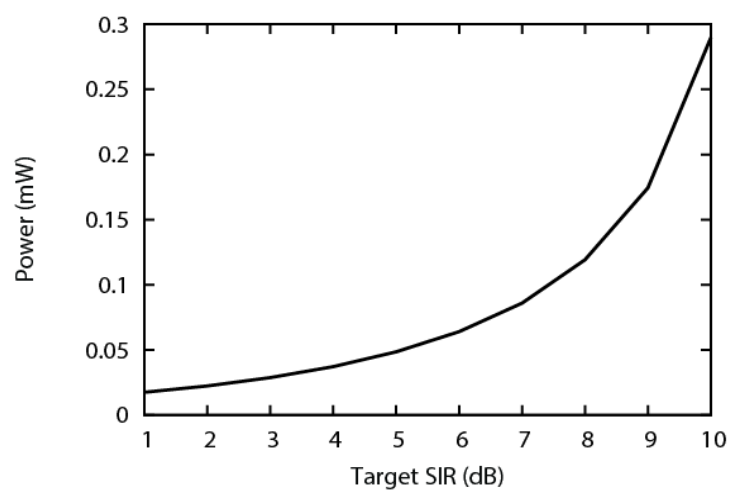

Figure 8. Power when target SIR is changed

Figure 9 shows that the SINR of each user will raise along with the increasing number of channels. Because of the more channels are provided, the user can use the channel easily without having to share with other users. It also has been shown in detail in Figure 5 when using multi channel, where the SINR of each user at the time uses three channels will be greater than the use of two channels or one channel.

The greater number of users in a channel group, the less value SINR can be obtained by the user in the group as shown in Figure 10. This is because among users will have more competitors in competition to get a part of channel for maintaining a better quality of service (QoS) that means have more interference, so that the achieved SINR will decrease. 


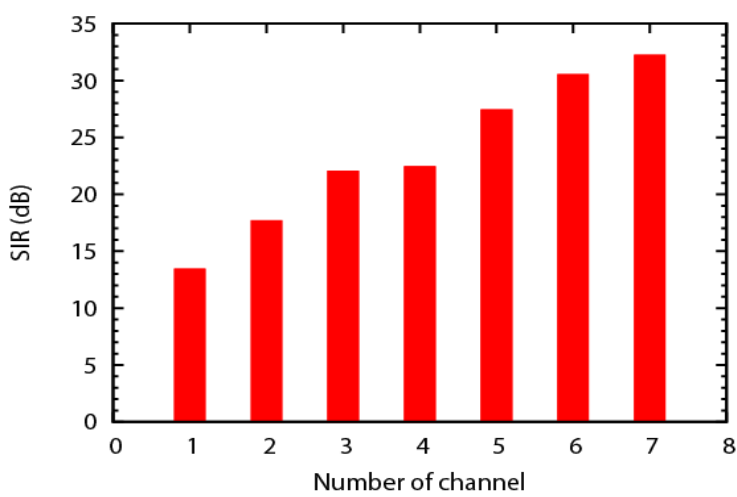

Figure 9. SIR when number of channel is changed

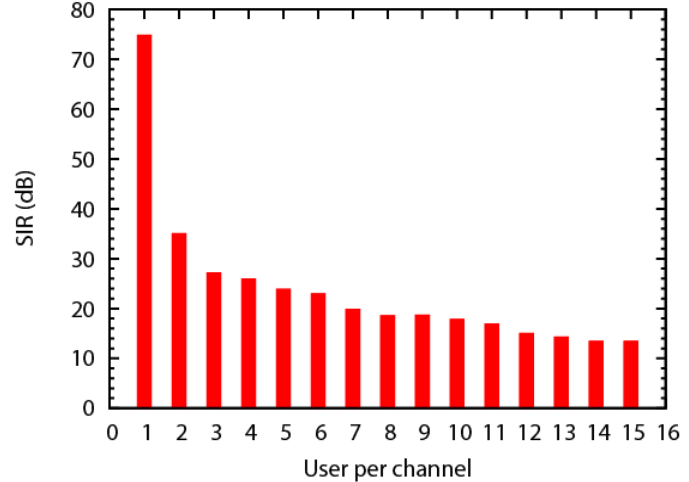

Figure 10. SIR in the addition of user per channel

Also, the results of feasibility test can also show the influence of the target SINR to the maximum amount of users that can be served, by reference to the power vector feasibility. This is shown in Figure 11. Based on the results of the feasibility test of the system can be concluded how many users the system is capable of being handled based on the non-negative power vector related to SINR target.

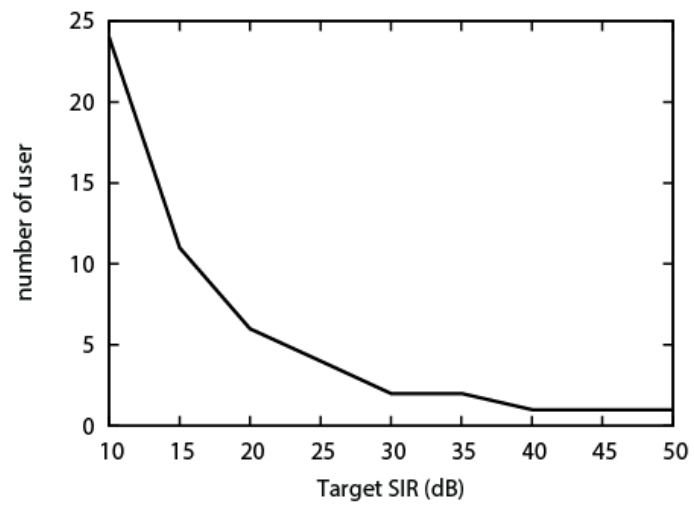

Figure 11. Target SIR when maximum number of user is changed

\section{CONCLUSION}

In this paper we have proved that by using the method feasible solution the studied power control scheme can be implemented as it shows that the result is always positive and achieve the target SINR for all users. Furthermore, we have lso demonstrated that the SINR users will increase when there are additional channels for user groups, and the average power of each user will decrease while increasing the amount of provided channels. The greater number of users in a user group, the less value of SINR obtained by the user in the group.

In the future works, the study on the feasibility of power control scheme in a distributed system using autonomous distributed power control and game theory method will be carried out as sustainability of this research.

\section{REFERENCES}

[1] D. T. Ngo, et al., "Distributed Interference Management in Two-Tier CDMA Femtocell Networks," IEEE Trans. Wirel. Commun., vol/issue: 11(3), pp. 979-989, 2012.

[2] S. Haykin, "Cognitive radio: brain-empowered wireless communications," IEEE J. Sel. Areas Commun., vol/issue: 23(2), pp. 201-220, 2005.

[3] J. Zander, "Performance of optimum transmitter power control in cellular radio systems," Veh. Technol. IEEE Trans. On, vol/issue: 41(1), pp. 57-62, 1992. 
[4] H. Koivo and M. Elmusrati, "Systems engineering in wireless communication," Hoboken, NJ, John Wiley \& Sons, 2009.

[5] V. Chandrasekhar, et al., "Power control in two-tier femtocell networks," IEEE Trans. Wirel. Commun., vol/issue: 8(8), pp. 4316-4328, 2009.

[6] R. D. Yates, "A framework for uplink power control in cellular radio systems," Sel. Areas Commun. IEEE J. On, vol/issue: 13(7), pp. 1341-1347, 1995.

[7] G. J. Foschini and Z. Miljanic, "A simple distributed autonomous power control algorithm and its convergence," IEEE Trans. Veh. Technol., vol/issue: 42(4), pp. 641-646, 1993.

[8] N. Amalia, et al., "Study on Feasible Solution of Power Control in Cognitive Radio Networks," presented at the ICSGTEIS 2014, Bali, pp. 58-61, 2014.

[9] N. Nie, et al., "A game theoretic approach to interference management in cognitive networks," in Wireless Communications, Springer, pp. 199-219, 2007.

[10] W. Li, et al., "Energy-efficient power allocation with dual-utility in two-tier OFDMA femtocell networks," in Globecom Workshops (GC Wkshps), 2012 IEEE, pp. 535-540, 2012.

[11] T. H. Chuang, et al., "Alleviating Interference through Cognitive Radio for LTE-Advanced Network," Int. J. Electr. Comput. Eng. IJECE, vol/issue: 5(3), pp. 539, 2015.

[12] T. Zahir, et al., "Interference Management in Femtocells," IEEE Commun. Surv. Tutor., vol/issue: 15(1), pp. 293$311,2013$.

[13] S. Yong and Q. Jiansheng, "Cognitive Radio Channel Selection Strategy Based on Experience-Weighted Attraction Learning," TELKOMNIKA Indones. J. Electr. Eng., vol/issue: 12(1), 2014.

[14] Y. Xu, et al., "Game-theoretic channel selection for interference mitigation in cognitive radio networks with blockfading channels," Wireless Communications and Networking Conference (WCNC), 2013 IEEE, pp. 303-308, 2013.

[15] H. N. Pham, et al., "QoS-aware channel selection in cognitive radio networks: a game-theoretic approach," in Global Telecommunications Conference, 2008. IEEE GLOBECOM 2008. IEEE, pp. 1-7, 2008.

[16] Z. Liang, et al., "Decentralized bit, subcarrier and power allocation with interference avoidance in multicell OFDMA systems using game theoretic approach," in Military Communications Conference, 2008. MILCOM 2008. IEEE, pp. 1-7, 2008.

[17] S. A. Saad, et al., "A Survey on Power Control Techniques in Femtocell Networks,” J. Commun., pp. 845-854, 2013.

[18] J. Mounzer, "Distributed Power Control Algorithms in Wireless Networking," 2009

[19] G. J. Foschini and Z. Miljanic, "Distributed autonomous wireless channel assignment algorithm with power control," Veh. Technol. IEEE Trans. On, vol/issue: 44(3), pp. 420-429, 1995.

[20] C. W. Sung and K. K. Leung, "A Generalized Framework for Distributed Power Control in Wireless Networks," IEEE Trans. Inf. Theory, vol/issue: 51(7), pp. 2625-2635, 2005.

[21] F. Li, et al., "A New Game Algorithm for Power Control in Cognitive Radio Networks," IEEE Trans. Veh. Technol., vol/issue: 60(9), pp. 4384-4391, 2011.

[22] P. X. - and Z. Q. -, "Power Control Based On Game Theory In Femtocell," Int. J. Digit. Content Technol. Its Appl., vol/issue: 6(18), pp. 357-366, 2012.

[23] X. Deng, et al., "A novel distributed power control based on game theory in cognitive wireless network," in Communications in China (ICCC), 2014 IEEE/CIC International Conference on, pp. 59-63, 2014.

[24] A. F. Isnawati, et al., "Feasible solution of centralized power control for multi channel cognitive femtocell network," in 2015 7th International Conference on Information Technology and Electrical Engineering (ICITEE), pp. 539-542, 2015.

\section{BIOGRAPHIES OF AUTHORS}

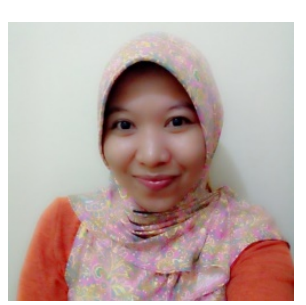

Anggun Fitrian Isnawati received Master degree in Telecommunication Engineering from Gadjah Mada University, Yogyakarta, Indonesia in 2011. She joined as a Lecturer in the Telkom School of Telematics (ST3 Telkom) since 2002. Currently she is a student on the Ph.D program at Departement of Electrical Engineering and Information Technology, Gadjah Mada University, Yogyakarta, Indonesia. She is currently member of Digital System and Electronic System laboratory at Universitas Gadjah Mada. Her research interests include telecommunication, cellular network, game theory and cognitive radio.

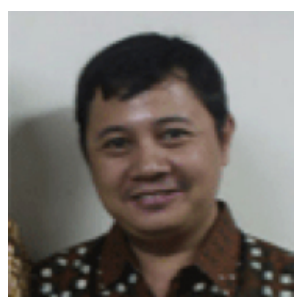

Risanuri Hidayat, Dr. Eng. He received Master in Information and Communication Technology from Agder University College, Norway, in 2002 and Doctor in Telecommunication Engineering, King Mongkut's Institute of Technology Ladkrabang (KMITL), Bangkok, Thailand, in 2009. He is now an Associate Professor at Department of Electrical Engineering and Information Technology, Gadjah Mada University. His interest is in Signal Processing, Digital and Analog Circuit Design, Telecommunication Systems, Data Communication and Networking, Java Programming and its Applications, and also Speech and Image Recognition. 


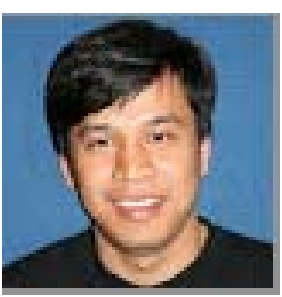

Selo Sulistyo is an Associate Professor in Information and Communication Technology at the Department of Electrical Engineering and Information Technology and also Head of Sistem Electronis laboratory at Gadjah Mada University. His research interests including Software Certification, Software Modeling, Domain Specific Languages, Mobile application development and Software Service Engineering which relates to the Internet of Things and connected objects.

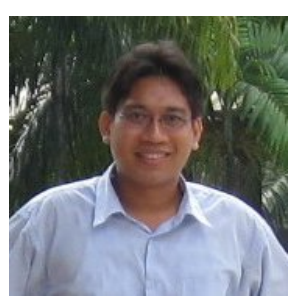

I Wayan Mustika., Ph.D. He received the B.Eng. degree in electrical engineering from Gadjah Mada University, Indonesia, in 2005, and the M.Eng degree in computer engineering from King Mongkut's Institute of Technology Ladkrabang (KMITL), Thailand, in 2008, and the Ph.D. degree in informatics from Kyoto University, Japan, in 2011. He is currently a Lecturer at Gadjah Mada University. He was a Student Activities Advisor of IEEE Indonesia Section in 2014 and he is currently a Secretary of IEEE Indonesia Section. His research interests include smart systems, machine-to-machine communications, and resource management in cognitive radio and heterogeneous networks with a particular emphasis on spectrum sharing and game theory. He received the Young Researcher's Encouragement Award from IEEE VTS Japan in 2010 and Student Paper Award from IEEE Kansai Section in 2011. He is now a Secretary of IEEE Indonesia Section. 